FEDERAL RESERVE BANK OF SAN FRANCISCO

WORKING PAPER SERIES

\title{
Unemployment Paths in a Pandemic Economy
}

\author{
Nicolas Petrosky-Nadeau and Robert G. Valletta \\ Federal Reserve Bank of San Francisco
}

September 2020

Working Paper 2020-18

https://www.frbsf.org/economic-research/publications/working-papers/2020/18/

\section{Suggested citation:}

Petrosky-Nadeau, Nicolas, Robert G. Valletta. 2020. "Unemployment Paths in a Pandemic Economy," Federal Reserve Bank of San Francisco Working Paper 2020-18. https://doi.org/10.24148/wp2020-18

The views in this paper are solely the responsibility of the authors and should not be interpreted as reflecting the views of the Federal Reserve Bank of San Francisco or the Board of Governors of the Federal Reserve System. 


\title{
Unemployment Paths in a Pandemic Economy
}

\author{
Nicolas Petrosky-Nadeau \\ Federal Reserve Bank of San Francisco
}

\author{
Robert G. Valletta \\ Federal Reserve Bank of San Francisco
}

September $2020^{*}$

\begin{abstract}
The COVID-19 pandemic upended the U.S. economy and labor market. We explore potential paths for the official unemployment rate through 2021. Our analyses rely on historical patterns of monthly flows in and out of unemployment, adjusted for unique features of the virus economy. The possible unemployment trajectories vary widely, but absent sustained hiring activity on an unprecedented scale, unemployment could remain substantially elevated into 2021. After adjusting the unemployment rate for unique measurement challenges created by virus containment measures, we find that unemployment has followed a fast recovery track during the first six months of the pandemic.
\end{abstract}

JEL Classification: E24, J21, J60.

Keywords: Labor market, unemployment, employment, labor force, COVID-19.

*Petrosky-Nadeau: FRB San Francisco, 101 Market Street, San Francisco CA 94105; e-mail: Nicolas.Petrosky-Nadeau@sf.frb.org. Valletta: FRB San Francisco, 101 Market Street, San Francisco CA 94105; e-mail: rob.valletta@sf.frb.org. Shelby Buckman and Amber Flaharty provided excellent research assistance. The views expressed are those of the authors and do not necessarily reflect the views of the Federal Reserve Bank of San Francisco or the Federal Reserve System. All remaining errors are our own. 


\section{Introduction}

The wave of initial job losses in response to the COVID-19 pandemic, and the resulting recession that began in early 2020, was massive. As measured by new claims for unemployment insurance (UI) in late March through mid-April, job losses during the first month of the pandemic response totaled about 25 million. This is nearly an order of magnitude larger than the largest losses that occurred during similar time frames in any other modern downturn, including the Great Recession of 2007-09.

Based on the initial labor market shock, we assess possible paths for the official unemployment rate for 2020 through 2021. The initial job losses and increase in unemployment were unprecedented, reflecting widespread business shutdowns and shelter-in-place policies intended contain the virus. The subsequent path of the unemployment rate is highly uncertain, reflecting two main sources of underlying uncertainty: (i) It is unclear how quickly the social distancing measures used to quell the pandemic will subside and therefore how quickly and to what degree economic activity and hiring will bounce back. (ii) With shelterin-place restrictions preventing active job search in most of the country, many UI recipients and other individuals who want work may not report themselves as unemployed, limiting the near-term increase in the official unemployment rate.

We incorporate these uncertainties in an empirical model in which changes in the unemployment rate are determined by the underlying monthly flows in and out of unemployment. We rely on a variety of data-based and judgmental assumptions about these flows to illustrate a range of possible paths for the unemployment rate through 2021.

In our scenarios, assuming the initial wave of job losers remain in the labor force, the unemployment rate quickly rises to about $20 \%$. Whether it stays in double-digits in 2021 depends on subsequent patterns in hiring behavior. History provides little guide about the likely pattern, given the unprecedented nature of the pandemic-induced disruptions. A return to pre-virus unemployment levels by sometime in 2021 would require a sustained pace of hiring activity that is much more rapid than recorded during any past recovery, which seems unlikely given the severity of disruptions to employment relationships, business ties to customers, and financial markets.

We also provide an initial assessment of the impact of changes in unemployment reporting and measurement. To this end, we project the initial increase in the measured unemployment rate assuming that a large fraction of job losers exit the labor force rather than engaging in active job search and hence being classified as unemployed. We assume that the shares of job losers who exit the labor force and enter unemployment follow their historical pattern in recessions. This reduces the initial increase in measured unemployment substantially. However, the smaller increase in unemployment is offset by a sharp decline in the measured labor force participation rate. Under these circumstances, some but not all of the unmeasured unemployment is likely to be reflected in future releases of the Bureau of Labor Statistics' (BLS) alternative measures of labor underutilization, most notably the U5 series that includes marginally attached individuals. Such alternative measures of labor market conditions, including the employment to population ratio, will be invaluable supplements to the unemployment rate for measuring the state of the labor market in the short and medium run.

Finally, given the availability of several months of data subsequent to our initial analysis, we are able to provide a partial assessment of the path of unemployment relative to our projections. To do so, we construct an adjusted unemployment rate that accounts for the unique measurement challenges created by the pandemic. Using the adjusted measure and data through August, we find that our unemployment projections based on a relatively fast recovery track the adjusted unemployment rate well.

Page 1 of 20 


\section{Unemployment during COVID-19}

\subsection{An initial wave of job losses}

New UI claims immediately soared due to the economic effects of the COVID-19 outbreak, with about 25 million new UI claims filed between the BLS reference weeks for measuring unemployment in the month of April 2020. ${ }^{1}$

A comparison with the experience during the Great Recession of 2007-09 provides a stark illustration of the severity of the current situation. Initial UI claims during the first month of the COVID-19 crisis approximately matched the cumulative claims during the worst nine-month period of the Great Recession: 22.3 million between September 2008 and the end of May 2009 (Figure 1 and appendix Table A1).

Typically, transitions from employment to unemployment exceed the number of initial UI claims, mainly due to UI ineligibility for some job separators. However, in recessions, monthly new UI claims tend to align closely with flows from employment to unemployment (EU) in the Current Population Survey (CPS) (see appendix Table A1 and Figure A1).

This close alignment is particularly clear during the Great Recession (see appendix Table A1). ${ }^{2}$ A similar close relationship between new UI claims and job loss was likely during the initial pandemic shock, given the broad expansion of UI eligibility that was part of the federal fiscal response to the crisis. However, the impact of these job losses on the measured unemployment rate may be limited by widespread shelter-inplace restrictions that preclude active job search and hence may cause many recent job losers to self-report as out of the labor force rather than unemployed. We return to this issue in Section 2, where we provide broad discussion about how much these measurement issues may affect the initial spike and subsequent patterns in the reported unemployment rate.

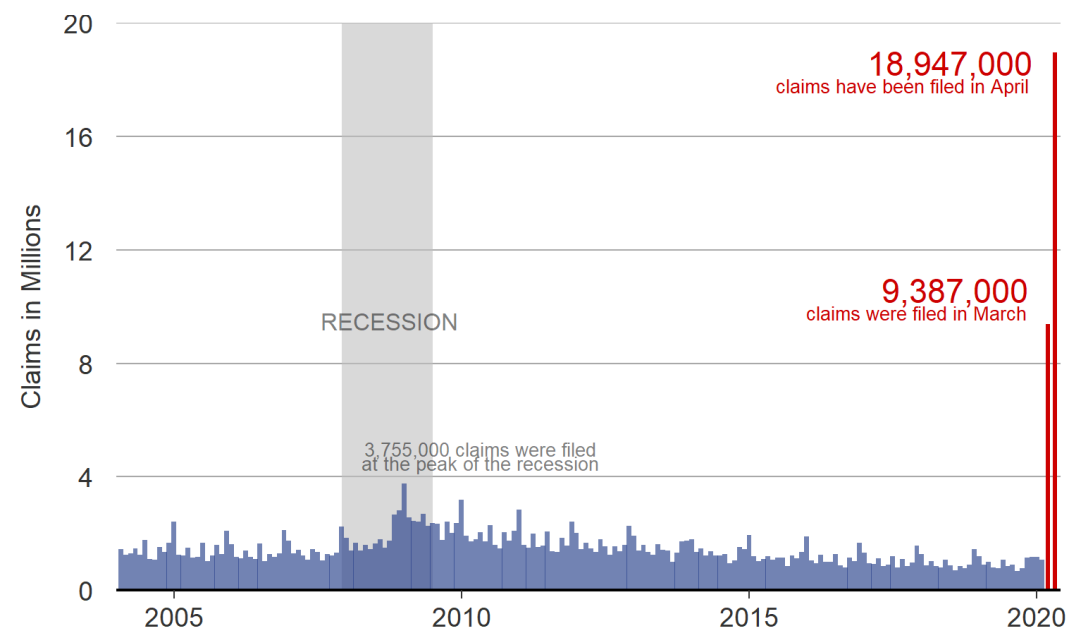

Figure 1: Initial unemployment insurance claims, monthly Notes: data are not seasonally adjusted. Data as of April 30, 2020.

\footnotetext{
${ }^{1}$ For the period covering the weeks ending March 21 through April 18, new UI claims on a non-seasonally adjusted basis were 2.9, $6.0,6.2,5.0$, and 4.3 million. The corresponding seasonally adjusted numbers were 3.3, 6.9, 6.6, 5.2 and 4.4 million. [Data as of April 30, 2020.]

${ }^{2}$ The close alignment between job loss and new UI claims during severe recessions likely reflects expanded availability of UI payments in conjunction with longer expected durations of unemployment, which induce more unemployed individuals to take up UI benefits.
} 


\subsection{A dynamic unemployment accounting framework}

Our approach to unemployment rate projections relies on modeling the underlying flow rates in and out of unemployment $(U)$ based on the labor market flow accounting equation (1). ${ }^{3}$

$$
U_{t}=U_{t-1}+\underbrace{\left(E U_{t}+N U_{t}\right)}_{U_{t}^{I n}}-\underbrace{\left(U E_{t}+U N_{t}\right)}_{U_{t}^{\text {Out }}}+o_{t}^{u}
$$

where $U_{t}^{I n}$ and $U_{t}^{\mathrm{Out}}$ are flows in and out of unemployment to or from either employment $(E)$ or out of the labor force (non-participation; $N$ ), and $o_{t}^{u}$ are other flows into in unemployment.

In particular, we work with the corresponding dynamic equation for the unemployment rate (2) with the appropriate separation and finding rates $\delta_{t}$ and $f_{t}$. We use standard terminology for these rates, but it is important to note that the separation rate includes both $E U$ and $N U$ inflows (entries) to unemployment and the finding rate includes both $U E$ and $U N$ outflows (exits) from unemployment.

$$
u_{t}=u_{t-1}+\underbrace{\delta_{t}\left(1-u_{t-1}\right)}_{u_{t}^{I n}=U_{t}^{I n} / L F_{t}}-\underbrace{f_{t} u_{t-1}}_{u_{t}^{\text {Out }}=U_{t}^{\text {Out }} / L F_{t}}+\tilde{o}_{t}^{u}
$$

In particular, the inflow rate into unemployment, $u_{t}^{I n}=U_{t}^{I n} / L F_{t}$ where $L F$ is the labor force $(E+U)$, is the product of the separation rate $\delta_{t}$ and the share of the population not in the unemployment pool in the previous period $\delta_{t} \times\left(1-u_{t-1}\right)$. The outflow rate from unemployment $u_{t}^{\text {Out }}=U_{t}^{\text {Out }} / L F_{t}$ is the product of the finding rate $f_{t}$ and the previous period's unemployment rate. ${ }^{4}$

\subsection{Initial spike in unemployment}

The initial shock to the labor market is obtained through the relationship of separation and finding rates $\delta_{t}$ and $f_{t}$ with the underlying flows:

$$
\begin{aligned}
\delta_{t} & =\frac{u_{t}^{I n}}{1-u_{t-1}}=\frac{N U_{t}+E U_{t}}{L F_{t} \times\left(1-u_{t-1}\right)} \\
f_{t} & =\frac{u_{t}^{\text {Out }}}{u_{t-1}}=\frac{U E_{t}+U N_{t}}{L F_{t} \times u_{t-1}}
\end{aligned}
$$

We assume, first, that the participation margin flows (via unemployment $U N$ and $N U$ and employment EN and NE) remain at their March 2020 levels in April, an assumption we discuss and relax further in section 2. This assumption leads to a decline in the labor force participation rate, from $62.7 \%$ in March to 62.1\% in April (see Table 1).

Next, we assume an April 2020 EU flow of 24.4 million based in the initial UI claims and, from (3), we obtain $\delta=0.168$ in April, up from 0.027 in March (see Table 1).

To project the unemployment rate path, we need to impose assumptions about subsequent job finding, about which we had limited information at the time of our initial projections. We assumed that April UE

\footnotetext{
${ }^{3}$ See for example Shimer (2012) and Sahin and Patterson (2012) for straightforward applications of a similar framework.

${ }^{4}$ Appendix B provides details on the correspondence between the unemployment accounting equations (1) and (2), as well as the correspondence between $\delta_{t}$ and the underlying $E U$ and $N U$ rates $\delta^{e u}$ and $\delta^{n u}$, and the correspondence between $f_{t}$ and the underlying $U E$ and $U N$ transition rates $f^{e u}$ and $f^{n u}$. The finding and separation rates are shown in appendix Figure A3. The other flows $o^{u}$ are very small, while the adjusted other flows $\tilde{o}_{t}^{u}=\frac{o_{t}^{u}}{L F_{t}}-u_{t-1}\left(\frac{L F_{t}-L F_{t-1}}{L F_{t}}\right)$ are quantitatively negligible as well.
} 
Table 1: Initial outbreak shock to unemployment inflows and outflows

\begin{tabular}{|c|c|c|c|c|c|}
\hline & \multicolumn{2}{|c|}{ Levels (Thsd.) } & & \multicolumn{2}{|c|}{ Rates (\%) } \\
\hline & Feb & March & & Feb & March \\
\hline$U_{t}$ & 5,787 & 7,140 & $u_{t}$ & 3.52 & 4.38 \\
\hline$U_{t}^{I n}$ & 3,059 & 4,225 & $\delta_{t}$ & 1.93 & 2.69 \\
\hline$E U_{t}$ & 1,532 & 2,660 & & & \\
\hline$N U_{t}$ & 1,527 & 1,565 & & & \\
\hline$U_{t}^{o u t}$ & 3,168 & 2,874 & $f_{t}$ & 53.79 & 50.16 \\
\hline$U E_{t}$ & 1,693 & 1,410 & & & \\
\hline$U N_{t}$ & 1,475 & 1,464 & & & \\
\hline$L F_{t}$ & 164,546 & 162,913 & $l f_{t}$ & 63.38 & 62.72 \\
\hline
\end{tabular}

Notes: Other unemployment flow $o_{t}^{u}$ not reported.

flows fell by one-third from their March level (from 1.4 million in March to 940,000). This results in a finding rate $f=0.34$ in April, down from 0.50 in March (see Table 1). ${ }^{5}$

Due to the initial spike in job losses combined with sharply reduced job finding, we projected that the unemployment rate would increase just over 14 percentage points between March and April, from $4.4 \%$ to $19.0 \%$, as the pool of job seekers rose from about 7 to 31 million individuals. ${ }^{6}$

\subsection{Projections beyond the initial of shock - full damage and the road to recovery}

\section{Job finding and separation rate paths: incorporating historical business cycle dynamics}

We explore a number of different scenarios for the evolution of the unemployment rate through the end of 2021. For all of our scenarios, we use the surge in job loss in response to the virus containment measures, assuming the sudden stop in economic activity is compressed entirely into the second quarter. This implies significant although declining job losses in May (7.8 million) and June (2.6 million) followed by a return of job losses to their prior historical trend beginning in July (1.4 million) (see Table A2).

The "COVID-19" (red) line of Figure 2a depicts the path for the separation rate $\delta_{t}$ that is shared in all of the scenarios (see also Table A3 for the corresponding values). We adopt this specification over the path implied by historical dynamics in the separation time series calculated from CPS micro data (blue line of Figure 2a) to incorporate the unique nature of the pandemic economy. ${ }^{7}$ The same figure plots the corresponding rates during the Great Recession for comparison (gray line).

The first scenario ("historical outflow dynamics") combines elements of historical business cycle dynamics and unique aspects of the pandemic economy. It incorporates the initial surge in job losses noted

\footnotetext{
${ }^{5}$ Although hiring rates appear to have picked up substantially in some sectors subsequent to the virus outbreak, such as online retail and grocery stores, anecdotal information suggests that overall hiring activity was quite limited. A lower hiring rate than we assume represents a downside risk to our projection.

${ }^{6}$ This estimate of the initial shock to the unemployment rate is broadly aligned with other recent estimates based on alternative methods (for example, Faria-e-Castro 2020, Wolfers 2020, Sahin and Yin 2020, Coibion et al. 2020, and Bick and Blandin 2020). However, the range of estimates is very wide, partly reflecting reporting issues that affect the distribution of job losses across unemployment and labor force exits (as discussed in Section 2). In Coibion et al. (2020) the vast majority of individuals flow into non-participation following job loss, while most are counted as unemployed in Bick and Blandin (2020). By contrast, Sahin and Yin (2020) spread the initial job losses already measured by new UI claims over several months, resulting in a somewhat more favorable path for the unemployment rate.

${ }^{7}$ The underlying inflow and outflow rates $\delta_{t}$ and $f_{t}$ are specified to follow AR processes (specifications and estimates are provided in appendix section B.2).
} 


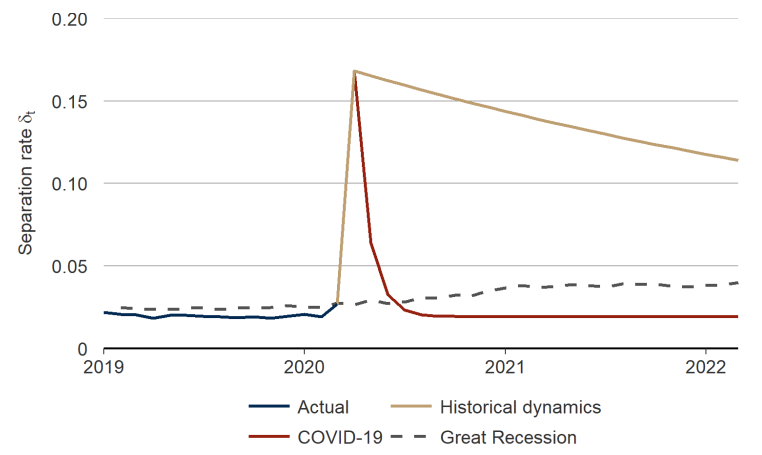

(a) Separation rate $\delta_{t}$

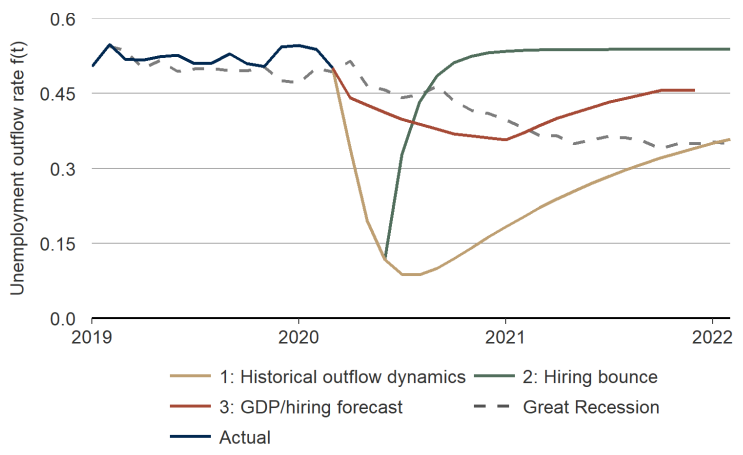

(b) Finding rate $f_{t}$

Figure 2: Paths for separation and finding rates under different scenarios

above and then relies on the business cycle dynamics embedded in the times series of the finding rate $f_{t}$. The path for $f_{t}$ that reflects historical dynamics in response to the initial shock is plotted in Figure $2 \mathrm{~b}$ (blue line). The same figure plots the corresponding rates during the Great Recession for comparison (gray line).

Our second scenario ("hiring bounce") incorporates very strong hiring activity following an assumed cessation of COVID-19 restrictions in July 2020, with an accelerated return to pre-outbreak unemployment exit rates (closing half the gap to the pre-outbreak level each month). This scenario provides a baseline for assessing the pace of hiring required to reverse the initial labor market shock. The finding rate in this scenario is essentially back to pre-outbreak levels by the end of the third quarter. By contrast, it remains at a fifth of the pre-outbreak rate in the historical outflow dynamics scenario. The resulting finding-rate path $f_{t}$ is plotted in Figure $2 \mathrm{~b}$ (green line). Although the finding rate returns to pre-outbreak levels, the implied pace of hiring is extremely high by historical standards given the very large pool of unemployed individuals from which that pace of hiring will occur. In particular, this scenario requires around 9 million hires from unemployment per month during the third quarter, a pace that is three to four times more rapid than the most rapid job finding rates observed during the recovery from the Great Recession. ${ }^{8}$

Our third scenario ("GDP/hiring forecast") relies on the historical relationship between GDP growth and overall exit rates from unemployment (to $E$ or $N$ ), which we calculated from CPS micro data. To project forward, we rely on the recent FRBSF forecast of GDP growth for 2020-21, which represents a relatively optimistic scenario for an economic recovery. ${ }^{9}$ We formed a projection of the unemployment exit rate by regressing it on four-quarter GDP growth. We then used the FRBSF forecast for GDP growth for the remainder of this year through 2021 to forecast the unemployment exit rate over this timeframe. ${ }^{10}$ The exit rate path $f_{t}$ under this scenario, shown as the purple line in Figure 2b, does not decline as much as in the first two scenarios, although it also shows a slower recovery back toward prior exit rates. ${ }^{11}$

\footnotetext{
${ }^{8}$ The most rapid rate recorded during the recovery from the Great Recession was 2.6 million in the second quarter of 2010.

${ }^{9}$ See Leduc (2020). Given the unusual degree of uncertainty surrounding economic projections at the time of the initial shock, Leduc discussed the GDP forecast in qualitative terms. For the primary or "best" scenario, the forecast contours include a sharp drop in GDP in the second quarter of 2020, followed by a partial bounce back in the second half of the year that leaves GDP down significantly for the year as a whole. Growth continues at a strong pace in 2021, fully overcoming the drop in 2020.

${ }^{10}$ We use data for 1986-forward for this exercise, due to GDP growth volatility prior to 1986. Figure A6a in the appendix illustrates that the overall exit rate from unemployment tracks GDP growth measured on a four-quarter basis relatively well. Sequential (onequarter) GDP growth is much noisier and hence does not track UE rates closely. We predict the overall exit rate from unemployment by regressing it on its own lagged value and contemporaneous 4-quarter growth in real GDP (the regression results are relatively robust to alternative lag structures for GDP growth).

${ }^{11}$ We also performed a preliminary assessment of the possible impact of the recent industry composition of job losses and expected job finding. Available reports suggest that layoffs have been concentrated in services sectors most directly affected by the virus containment measures, including retail stores, leisure and hospitality, entertainment, and personal services. Figure A6b in the appendix shows that the cyclical pattern of job-finding rates in these heavily affected sectors is similar to the economy-wide average. We there-
} 


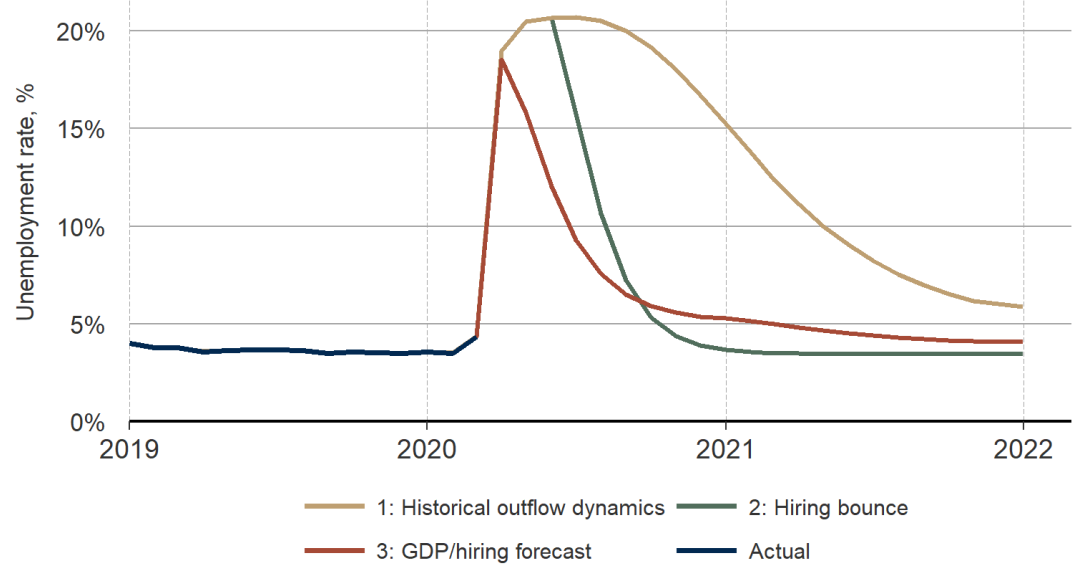

Figure 3: Paths for the unemployment rate under different scenarios

\section{Projected paths for the unemployment rate}

The paths for the unemployment rate under the various scenarios are shown in Figure 3 (and Table A3 of the appendix, while Table A2 reports the levels).

In the "historical outflow dynamics" scenario (yellow line), unemployment quickly peaks near 20\% and then stays in double digits through early 2021. The "hiring bounce" scenario (green line in panel (a) of Figure 3) reflects an assumed stronger recovery in hiring activity. The unemployment rate drops much more rapidly than in the "historical outflow dynamics" scenario. At the end of 2020 most of the job losses have been reversed, with unemployment close to its pre-virus levels. As noted earlier, this scenario requires that hiring occur at a pace that is much faster than historical norms during economic expansions-for example, at a pace about three to four times that observed early in the recovery from the Great Recession.

The scenario based on the relationship between unemployment exits and GDP growth ("GDP/hiring forecast") is shown as the purple line in Figure 3. The unemployment path shows unemployment peaking in the second quarter at about $17 \%$, lower than in the "historical outflow dynamics" or "hiring bounce" scenarios, with a subsequent decline that is more rapid than in either of the alternatives shown. In this scenario, the unemployment rate returns near its pre-virus level by the middle of 2021. Compared with the other scenarios, there is a somewhat more modest initial impact and less persistent effects on the unemployment rate due to the underlying limited changes in the finding rate $f_{t}$. This scenario, based on the response of hiring activity to forecasted GDP growth, may by overly optimistic by understating the magnitude and persistence of the reduction in hiring due to the COVID-19 crisis.

These projections encompass a range of possible paths for the unemployment rate in 2020 and 2021in response to the COVID-19 shock. They rely heavily on historical patterns in labor market dynamics that may not accurately capture the shock and recovery path for the current unprecedented situation. A more pronounced bounce-back in hiring activity versus historical norms is possible, as reflected in our second scenario above ("hiring bounce") in which the unemployment rate normalizes by the middle of 2021 . However, that scenario may be overly optimistic, given the possibility of profound labor market dislocations created by the unprecedented wave of initial job losses.

fore chose to focus on overall rather than industry-specific exit rates from unemployment. 


\section{Challenges to measuring unemployment during the outbreak and re- covery}

As noted earlier, the increase in measured unemployment arising from the virus shock may be limited by widespread shelter-in-place restrictions that preclude active job search and hence may cause many job losers to report themselves as out of the labor force (EN transitions) rather than unemployed (EU transitions). We explore the potential impact of these measurement issues via alternative assumptions about flow rates between different labor market states. ${ }^{12}$

\subsection{Possible changes to flows in and out of the labor market}

To assess the role of unemployment measurement and reporting issues, we consider how alternative paths for participation could impact the measured unemployment rate. Changes in the size of the labor force can be partitioned into components arising from flows along the employment margin ( $N E$ and $E N$ flows) and the unemployment margin (NU and UN flows): ${ }^{13}$

$$
L F_{t}=L F_{t-1}+\underbrace{\left(N E_{t}-E N_{t}\right)}_{\text {E margin }}+\underbrace{\left(N U_{t}-U N_{t}\right)}_{\text {U margin }}
$$

For this exercise, we maintain the assumption from the earlier scenarios of constant flows levels between unemployment and non-participation. In particular we fix the contribution of the unemployment margin to changes in the labor force to its sample average (1990 to 2020), setting $N U_{t}-U N_{t}=\overline{N U-U N}$ for all $t$. This assumption is supported by observing that the two components of the unemployment margin track each other closely, hence the gap between them remains relatively constant over time (see panels (a) and (b) of appendix Figure A10).

Moreover, changes in flows along the unemployment margin with non-participation are not a significant contributor to changes in the labor force over time horizons considered in our scenarios. Constructing a counterfactual labor force participation rate from the labor force flow accounting equation (5), but setting $N U_{t}-U N_{t}=\overline{N U-U N}$ from the start of the Great Recession, tracks the actual labor force participation rate very closely. The same is true during a more recent period (green lines in Figures A2 (a) and (b)). As a result we rely on fixed flow levels between unemployment and non-participation as an empirically reasonable assumption. In addition, the corresponding counterfactual rate of unemployment tracks the actual rate of unemployment closely as well (see appendix Figure A7).

Our second assumption is to take as given the path for employment from the "historical outflow dynamics" scenario but to alter the breakdown of flows between employment and non-participation and flows between employment and unemployment (decomposing the employment outflows and inflows $E^{\text {out }}$ and $E^{I n}$ in equation 6):

$$
E_{t}=E_{t-1}+(\underbrace{U E_{t}+N E_{t}}_{E_{t}^{I n}})-(\underbrace{E U_{t}+E N_{t}}_{E_{t}^{\text {Out }}})+o_{t}^{E}
$$

\footnotetext{
${ }^{12}$ Given the large direct employment losses due to the virus containment measures, the level of employment and the employmentto-population ratio may serve as a reliable alternative indicators of labor market conditions that sidestep the labor force measurement issues we explore in this section. With that consideration in mind, the level of employment and the employment to population ratio implied by the "historical outflow dynamics" and "hiring bounce" scenarios from Section 1 are plotted in Figure A8. The employment to population ratio is projected to dip below $50 \%$ by mid-2020 and recover through 2021.

${ }^{13}$ We omit other flows $l_{t}^{l}$, which are small, to ensure the accounting identity holds in the data.
} 


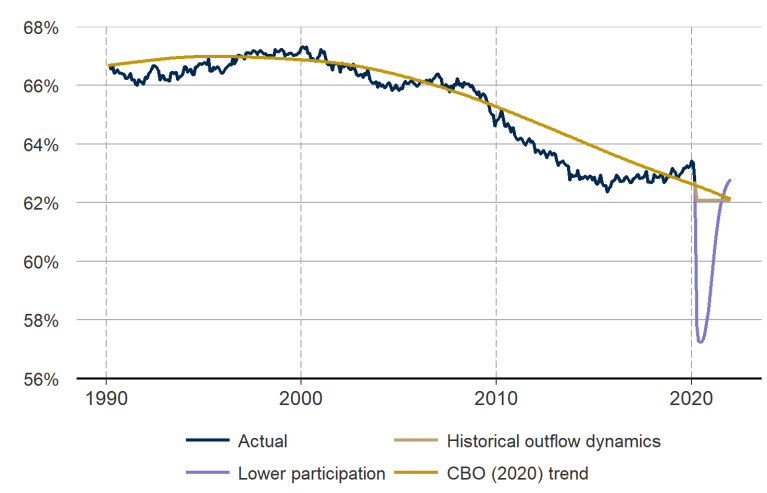

(a) Labor force participation rate

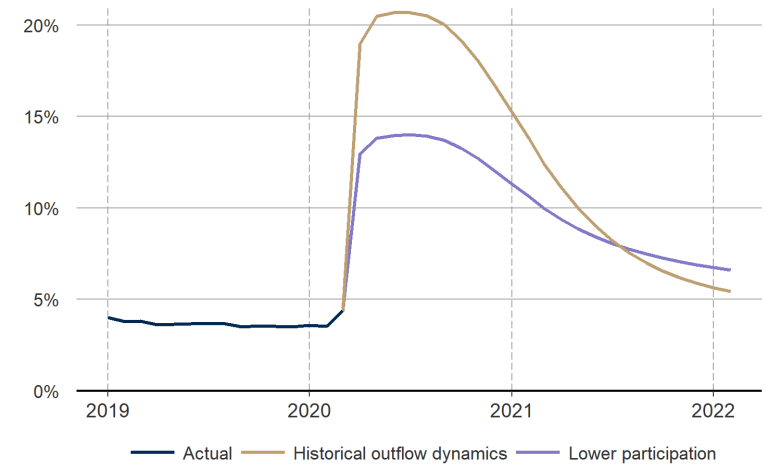

(b) Unemployment rate

Figure 4: Alternate paths for the participation and unemployment rates

To do so, we define $\tau_{U E, t}=\frac{E U_{t}}{E_{t}^{\text {Out }}}$, as the share of employment outflows going to unemployment and $\tau_{E U, t}=$ $\frac{U E_{t}}{E_{t}^{I n}}$ as the share of employment inflows coming from unemployment. EU flows are typically 33 percent of employment outflows. The proportion rises during the initial phase of recessions, for example from 0.30 prior to the start of the Great Recession to nearly 0.45 at the peak (see panel (a) of Figure A9). UE flows are typically 36 percent of employment inflows and mirror the unemployment share of outflows $\tau_{E U}$ (see panel (b) of Figure A9). ${ }^{14}$

In the baseline scenarios we had assumed that $E N$ and $N E$ flows were fixed to their March levels, implying $81 \%$ of employment outflows in April transition to unemployment $\left(\tau_{E U, t}=E U_{t} / E_{t}^{\text {Out }}=0.81\right) .{ }^{15}$ We build a fourth scenario closer to the historical breakdown during recessions, assuming an initial peak at $45 \%$ followed by a gradual return to pre-crisis shares for both $\tau_{U E, t}$ and $\tau_{E U, t}$ (blue lines in Figure A9), and applying this breakdown of employment outflows and inflows to the paths from the "historical outflow dynamics" scenario. ${ }^{16}$

The resulting paths for the labor force participation and unemployment rates are shown in panels (a) and (b) of Figure 4, respectively. The Congressional Budget Office's (CBO) estimate of the underlying trend participation rate is overlaid in Figure 4 (a) for comparison (specifically the figure reports the estimate described in Congressional Budget Office 2020). In the alternative LFPR scenario the participation rate drops precipitously to $57.2 \%$. By the end of 2020 it is back to $59 \%$, and a little above the CBO trend at the end of 2022. The measured unemployment rate (panel (b)) initially increases to $13 \%$ and peaks at $14 \%$ in mid-2020. It crosses paths with the baseline "historical outflow dynamics" scenario in mid-2021 at 7.7\%.

This exercise indicates that accounting for the full range of labor force flows requires numerous assumptions. However, the results illustrate that the increase in measured unemployment in the near to medium term following the initial virus shock may be tempered by increased flows out of the labor force, assuming that historical flow patterns prevail. This should not be interpreted as indicating less severe labor market disruption than projected in our initial unemployment scenarios. Instead, the scenario in this section illustrates that the disruption to the labor market may be partially absorbed via labor force drop-outs rather

\footnotetext{
${ }^{14}$ The series $\tau_{E U, t}$ and $\tau_{U E, t}$ have a contemporaneous correlation of 0.9 .

${ }^{15}$ Figure A9 plots the baseline scenario implications for $\tau_{E U}$ and $\tau_{U E}$. The share of employment inflows coming from unemployment increased to $\tau_{U E}=0.50$ in May after an initial decline in April.

${ }^{16}$ The employment to unemployment flows for this scenario are obtained as $E U_{t}^{\text {alt }}=\tau_{E U, t}^{a l t} E_{t}^{\text {Out }}$, where $E_{t}^{\text {Out }}$ corresponds to the employment outflows from scenario 1, and the flows to non-participation as $E N_{t}^{a l t}=E_{t}^{\text {Out }}-E U_{t}^{a l t}$. The unemployment to employment flows for this scenario are obtained as $U E_{t}^{\text {alt }}=\tau_{U E, t}^{a l t} E_{t}^{I n}$, where $E_{t}^{I n}$ corresponds to the employment outflows from scenario 1 , and the flows to non-participation as $N E_{t}^{\text {alt }}=E_{t}^{I n}-U E_{t}^{a l t}$.
} 
than active job search.

\subsection{Assessing the state of the labor market going forward}

Even with direct survey measurement, uncertainty about reporting on labor market status was expected to be very large during the pandemic. ${ }^{17}$ As discussed above, many of the initial job losers may flow into $\mathrm{N}$ rather than $U$ and perhaps remain out of the labor force for an extended period in response to sustained virus containment measures. The resulting reduction in the measured unemployment rate during the early months of the virus is likely to be offset by higher unemployment later. This could occur because many of the job losers who report themselves as transitioning directly out of the labor force are likely to initiate active job search once social distancing restrictions are lifted, thereby transitioning into $U$ from $N$.

Many of the job losers who initially transition into $\mathrm{N}$ rather than $\mathrm{U}$ due to the pandemic are likely to appear among the group of labor force non-participants who are "marginally attached" or state that they "want a job." The former group includes individuals who are not in the labor force but want and are available for work and have looked for a job sometime in the prior 12 months. This group is included in the BLS alternative measures of labor underutilization, specifically the U5 measure. By contrast, the "want a job" group includes the marginally attached but is larger, lacking the restriction of active job search within the past 12 months. Many job losers who exit the labor force due to pandemic restrictions on job search are likely to be in the "want a job" group, which is not fully incorporated into any of the BLS' alternative measures of labor underutilization. BLS data show that the size of this group has indeed increased substantially since early 2020, suggesting that a large portion of the $\mathrm{E}$ to $\mathrm{N}$ flows during the initial months of the pandemic represent a form of "hidden unemployment."

An additional form of "hidden unemployment" due to the unique reporting issues related to the virus was recognized by BLS from the outset of the pandemic impact. Beginning in March 2020, their monthly Employment Situation reports included an assessment of the virus' impact on data collection and reporting. In particular, the BLS noted that a large number of household survey respondents who were laid off and hence unemployed according to standard definitions were classified as employed but absent from work. The agency estimated that this misclassification error reduced the unemployment count by 8.1 million in April 2020. Including these individuals in the pool of unemployed would have increased the unemployment rate by 5 percentage points (BLS 2020).

\subsection{Unemployment paths six months into the pandemic recession}

We develop an adjusted unemployment rate series that reflects the two forms of "hidden unemployment" discussed in the preceding sub-section. This adjusted series incorporates the increase in the size of the two groups - out of the labor force but "want a job" and "employed but absent without pay" - relative to their levels prior to the onset of the pandemic (the average of January and February 2020). The intent is to capture the discontinuous jump in these series caused by the pandemic. The adjusted unemployment rate is obtained by adding the increases in these categories of workers to the pool of unemployed.

Figure 5 compares the resulting adjusted unemployment rate to the official unemployment rate (light blue and dark blue, respectively). The figure also incorporates the data released in the months since the

\footnotetext{
${ }^{17}$ For instance, during the initial wave of shut downs, Bick and Blandin (2020) and Coibion et al. (2020) used real-time surveys intended to mimic official BLS labor force statistics from the CPS. They reached widely varying conclusions about the unemployment rate in April, with Bick and Blandin finding nearly a 16 percentage point increase and Coibion et al. finding only a 2 percentage point increase. The gap between them is reflected in corresponding differences in non-participation rates.
} 


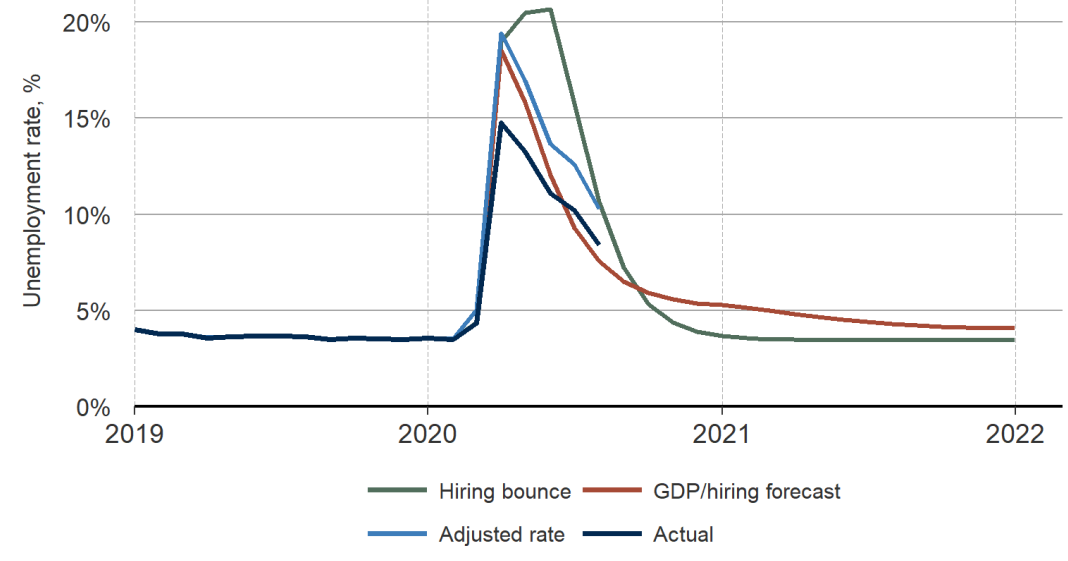

Figure 5: Actual and adjusted rates of unemployment during the pandemic recession

original formulation of our unemployment projections (May through August, 2020). To put the path of the actual and adjusted unemployment rates in perspective relative to our initial projections, the figure displays the projections under the hiring bounce and GDP/Hiring forecast scenarios described earlier.

Compared to the official 23 million unemployed in April 2020, our adjustment adds nearly 9 million unemployed, increasing the April unemployment rate to $19.4 \%$. This is slightly above our baseline projection of a 19.0\% unemployment rate in April. The gap between the official and adjusted number unemployed fell slightly in May, to 7 million, and narrowed more significantly over the following months to 3 million in August. As a result, the gap between the official unemployment rate and our adjusted rate fell from 4.7 percentage points in April to 1.8 percentage points in August. Overall, although our projected unemployment paths in general are somewhat high relative to the official unemployment rate during the early months of the pandemic recession, our projections based on a relatively fast recovery align closely with the path of the adjusted unemployment rate that accounts for unique measurement challenges during the pandemic recession.

\section{Conclusion}

With the massive initial job losses caused by the economic response to the COVID-19 virus and resulting containment measures, the official U.S. unemployment rate surged during the spring of 2020. We assessed potential paths of the unemployment rate from Spring 2020 through the end of 2021 . We relied on an analytical approach that combines historical labor market dynamics with judgmental assessments of the scale of initial job losses and potential hiring behavior as the economy and employers adjust to the virus shock. Our analysis accurately projected that the unemployment rate would exceed by a substantial margin its highs reached in any other downturn since World War II. Our projections also indicate that unemployment is likely to remain quite elevated into 2021, especially after we account for measurement challenges that cause the official unemployment rate to exclude individuals who would be actively seeking work if they did not face the constraints imposed by virus containment measures.

Looking ahead, tremendous uncertainty surrounds projections for the path of the unemployment rate over the next few years, so we have not claimed that any specific scenario qualifies as "likely." On the 
pessimistic side, absent a historically unprecedented burst of hiring later this year and next year, the unemployment rate could remain in double digits through 2021. From a more optimistic perspective, if the shutdowns in response to the virus are lifted quickly, and employers capitalize on the large pool of available workers by ramping up hiring quickly, the unemployment rate could be back down near its pre-virus level by mid-2021. Future research may help fine tune these assessments by focusing on the the disparate effects of the outbreak across industries, firm size, types of jobs, and the path of the pandemic itself. For example, Dingel and Neiman (2020) provide an initial estimate of the occupations most affected by lockdowns, in terms of the feasibility of performing work remotely, and conclude that a third of jobs could be performed at home. Cajner et al. (2020) use preliminary payroll data to estimate employment on a weekly basis for a variety of industries during the pandemic.

As we discussed, uncertainty about the path of the unemployment rate is exacerbated by measurement ambiguities surrounding the self-reported labor force status of non-employed individuals whose job search is precluded by shelter-in-place restrictions. We explored alternative paths for the unemployment and labor force participation rates allowing for the possibility that many job losers will drop out of the labor force and slowly re-enter it over time. This would temper the increase in unemployment but at the expense of a corresponding sharp drop in the labor force participation rate. Given the implied uncertainty about the measurement of labor market conditions going forward, it is imperative to closely monitor a wide range of available labor market indicators to assess how the U.S. labor market is evolving in response to the COVID-19 shock.

\section{References}

Bick, A. \& Blandin, A. (2020). "Real Time Labor Market Estimates During the 2020 Coronavirus Outbreak", Arizona State University manuscript (April).

Bureau of Labor Statistics. (2020). Frequently asked questions: The impact of the coronavirus (covid-19) pandemic on the employment situation for april 2020, https:/ /www.bls.gov/cps/employment-situationcovid19-faq-april-2020.pdf.

Cajner, T., Crane, L. D., Decker, R. A., Hamins-Puertolas, A., \& Kurz, C. (2020). "Tracking Labor Market Developments during the COVID-19 Pandemic: A Preliminary Assessment", Federal Reserve Board Discussion Series 2020-030 (April).

Christiano, L. J. \& Fitzgerald, T. J. (2003). The band pass filter. International Economic Review, 44(2), 435-465.

Coibion, O., Gorodnichenko, Y., \& Weber, M. (2020). "Labor Markets During the COVID-19 Crisis: A Preliminary View", University of Texas - Austin manuscript (April).

Congressional Budget Office. (2020). "The Budget and Economic Outlook: 2020 to 2030", Report 56020 (January), https://www.cbo.gov/publication/56020.

Dingel, J. \& Neiman, B. (2020). "How Many Jobs Can be Done at Home?", Becker Friedman Institute (March).

Faria-e-Castro, M. (2020). "Back-of-the-Envelope Estimates of Next Quarter's Unemployment Rate", FRBSL On the Economy Blog (March).

Leduc, S. (2020). "FedViews", Federal Reserve Bank of San Francisco, April 6.

Sahin, A. \& Patterson, C. (2012). "The Bathtub Model of Unemployment: The Importance of Labor Market Flow Dynamics", FRBNY Liberty Street Economics blog (March). 
Sahin, A. \& Yin, J. (2020). "Unemployment projections and employment subsidies", University of Texas Austin manuscript (April).

Shimer, R. (2012). Reassessing the ins and outs of unemployment. Review of Economic Dynamics, 15(2), 127148.

Wolfers, J. (2020). "The Unemployment Rate Is Probably Around 13 Percent", New York Times (The Upshot, April 6). 


\section{Online Appendix}

\section{A Additional tables and figures}

Table A1: Estimates of job losses

\begin{tabular}{|c|c|c|c|c|c|c|}
\hline & \multicolumn{3}{|c|}{ COVID 19 Outbreak } & \multicolumn{3}{|c|}{ Great Recession (2007-09) } \\
\hline & \multicolumn{3}{|c|}{2020} & \multirow{2}{*}{$\begin{array}{c}\text { Peak } \\
02 / 09\end{array}$} & \multicolumn{2}{|c|}{ Cumulative } \\
\hline & Feb & March & April & & $\begin{array}{l}12 / 07- \\
05 / 09^{a}\end{array}$ & $\begin{array}{l}09 / 08 \\
05 / 09^{a}\end{array}$ \\
\hline Initial UI Claims $^{b}$ & 1,052 & 930 & 24,379 & 2,484 & 37,188 & 22,256 \\
\hline E to $\mathrm{U}$ flows ${ }^{c}$ & 1,532 & 2,660 & $24,379^{d}$ & 2,834 & 36.179 & 20,086 \\
\hline
\end{tabular}

Notes: Data as of April 30, 2020. a. Cumulative initial claims between Dec. 1, 2007 and May 30, 2009, and between Sept. 1, 2009 and May 30, 2009; b. Cumulative for the weeks through the one that includes the 12th of the month. For Feb. 2020 that includes the weeks ending Jan. 18, 25, Feb. 1, 8 and 15. For March 2020 that includes the weeks ending Feb. 22, 29, March 7 and 14. For April 2020 that includes the weeks ending March 21, 28, April 9, 11 and 18. For Feb. 2009 that includes the weeks ending Jan. 24, 31, Feb. 7 and 14.; c. Monthly flow from employment to unemployment, CPS. d: Assumed.

Table A2: Unemployment levels under different scenarios

\begin{tabular}{|c|c|c|c|c|c|c|c|c|c|c|}
\hline & $\begin{array}{r}2020 \\
\text { April } \\
\end{array}$ & May & June & July & Aug. & Sept. & Oct. & Nov. & Dec. & $\begin{array}{r}2021 \\
\text { Dec }\end{array}$ \\
\hline \multicolumn{11}{|l|}{$U_{t}$} \\
\hline Official & 23,078 & 20,985 & 17,750 & 16,338 & 13,550 & & & & & \\
\hline Adjusted & 32,161 & 28,058 & 22,487 & 20,656 & 16,869 & & & & & \\
\hline \multicolumn{11}{|c|}{1 - Historical outflow dynamics } \\
\hline$U_{t}$ & 30,682 & 32985 & 33311 & 33349 & 33058 & 32260 & 30907 & 29073 & 26903 & 9481 \\
\hline$U_{t}^{I n}$ & 25,944 & 8360 & 4193 & 2981 & 2620 & 2518 & 2501 & 2517 & 2550 & 2917 \\
\hline$U_{t}^{\text {Out }}$ & 2,404 & 5952 & 3867 & 2943 & 2912 & 3315 & 3854 & 4352 & 4720 & 3397 \\
\hline \multicolumn{11}{|c|}{2 - Hiring bounce } \\
\hline$U_{t}$ & 28,343 & 32985 & 33311 & 25381 & 17182 & 11673 & 8601 & 7036 & 6272 & 5580 \\
\hline$U_{t}^{I n}$ & 23,605 & 8360 & 4193 & 2981 & 2783 & 2830 & 2900 & 2948 & 2975 & 3001 \\
\hline$U_{t}^{\text {Out }}$ & 2,404 & 5952 & 3867 & 10911 & 10983 & 8338 & 5972 & 4513 & 3738 & 3001 \\
\hline \multicolumn{11}{|c|}{3 - GDP / hiring forecast } \\
\hline$U_{t}$ & 29,870 & 25,531 & 19,440 & 15,007 & 12,175 & 10,493 & 9,544 & 8,990 & 8,682 & 6,580 \\
\hline$U_{t}^{I n}$ & 25,954 & 8,405 & 4,436 & 3,304 & 2,995 & 2,928 & 2,923 & 2,930 & 2,937 & 2,981 \\
\hline$U_{t}^{\text {Out }}$ & 3,089 & 12,745 & 10,527 & 7,737 & 5,828 & 4,610 & 3,872 & 3,484 & 3,245 & 3,016 \\
\hline
\end{tabular}


Table A3: Unemployment rates under different scenarios

\begin{tabular}{|c|c|c|c|c|c|c|c|c|c|c|}
\hline & $\begin{array}{l}2020 \\
\text { April } \\
\end{array}$ & May & June & July & Aug. & Sept. & Oct. & Nov. & Dec. & $\begin{array}{r}2021 \\
\text { Dec } \\
\end{array}$ \\
\hline \multicolumn{11}{|l|}{$u_{t}$} \\
\hline Official & 14.75 & 13.26 & 11.10 & 10.22 & 8.42 & & & & & \\
\hline Adjusted & 19.42 & 16.97 & 13.65 & 12.58 & 10.28 & & & & & \\
\hline \multicolumn{11}{|c|}{1 - Historical outflow dynamics } \\
\hline$u_{t}$ & 19.03 & 20.46 & 20.66 & 20.68 & 20.50 & 20.01 & 19.17 & 18.03 & 16.68 & 5.88 \\
\hline$\delta_{t}$ & 16.83 & 6.40 & 3.27 & 2.33 & 2.05 & 1.96 & 1.94 & 1.93 & 1.93 & 1.93 \\
\hline$f_{t}$ & 34.02 & 19.47 & 11.72 & 8.83 & 8.73 & 10.03 & 11.95 & 14.08 & 16.23 & 34.10 \\
\hline \multicolumn{11}{|c|}{2 - Hiring bounce } \\
\hline$u_{t}$ & 19.03 & 20.46 & 20.66 & 15.74 & 10.66 & 7.24 & 5.33 & 4.36 & 3.89 & 3.46 \\
\hline$\delta_{t}$ & 16.83 & 6.40 & 3.27 & 2.33 & 2.05 & 1.96 & 1.94 & 1.93 & 1.93 & 1.93 \\
\hline$f_{t}$ & 34.02 & 19.47 & 11.72 & 32.76 & 43.27 & 48.53 & 51.16 & 52.47 & 53.13 & 53.79 \\
\hline \multicolumn{11}{|c|}{3 - GDP / hiring forecast } \\
\hline$u_{t}$ & 18.52 & 15.83 & 12.05 & 9.31 & 7.55 & 6.51 & 5.92 & 5.57 & 5.38 & 4.08 \\
\hline$\delta_{t}$ & 16.83 & 6.40 & 3.27 & 2.33 & 2.05 & 1.96 & 1.94 & 1.93 & 1.93 & 1.93 \\
\hline$f_{t}$ & 44.10 & 42.67 & 41.23 & 39.80 & 38.83 & 37.87 & 36.90 & 36.50 & 36.10 & 45.60 \\
\hline
\end{tabular}

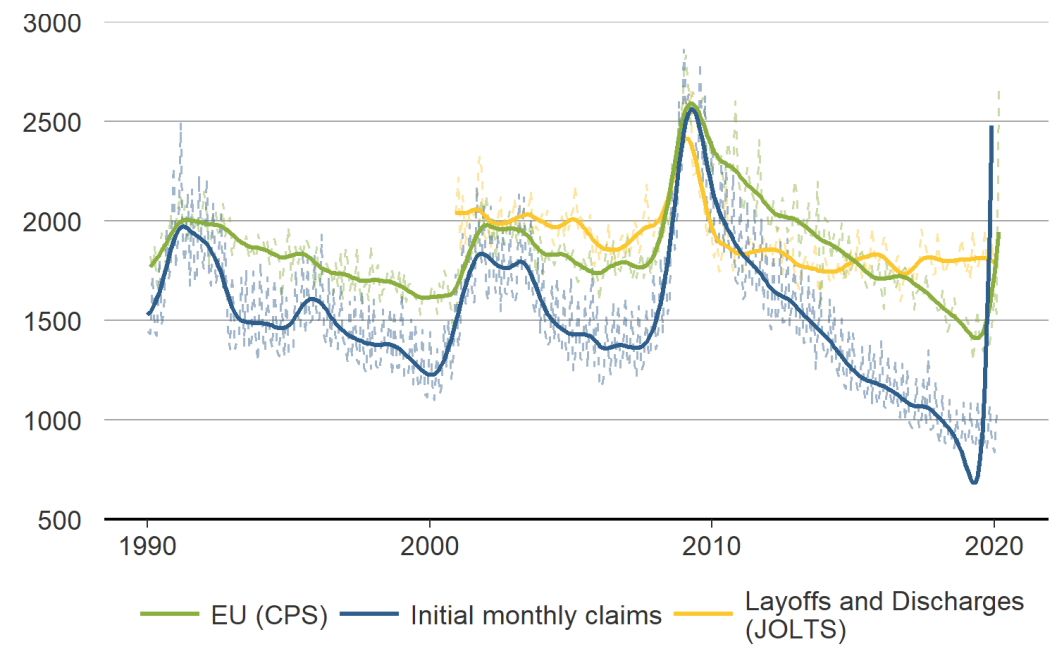

Figure A1: Initial UI claims, Layoffs and Discharges (JOLTS) and flows from employment to unemployment (EU, CPS), monthly. . Notes: Dashed lines: raw data; solid lines: high frequency HP trend. Data as of April 30, 2020. 


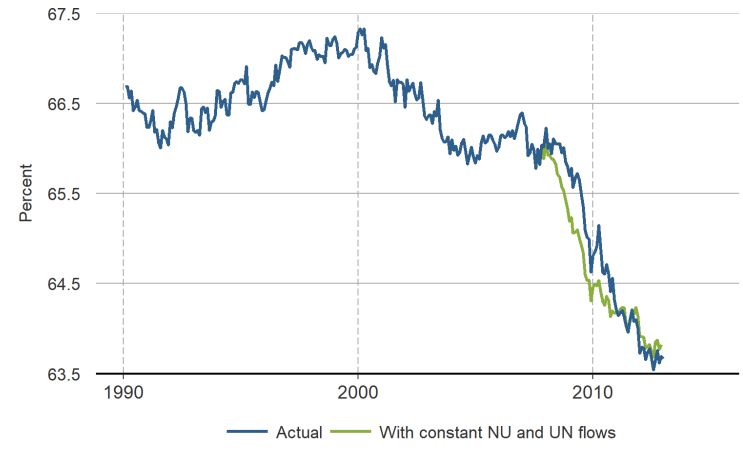

(a) Great Recession

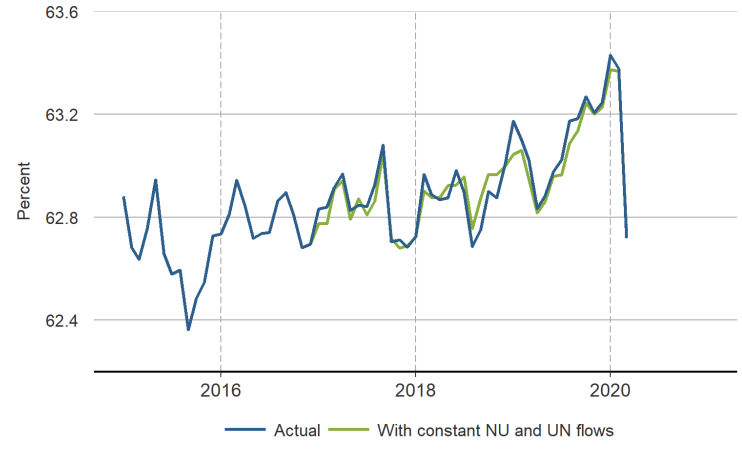

(b) Recent period

Figure A2: Labor force participation rate: actual and imposing fixed $N U$ and $U N$ flows

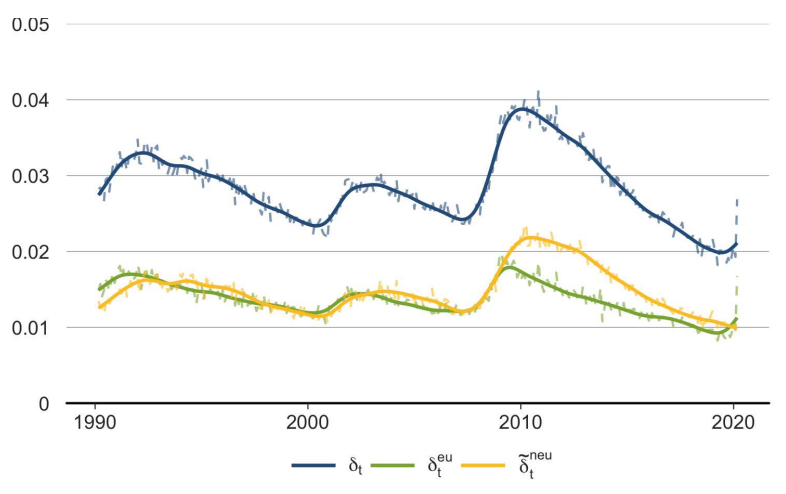

(a) Separation Rates

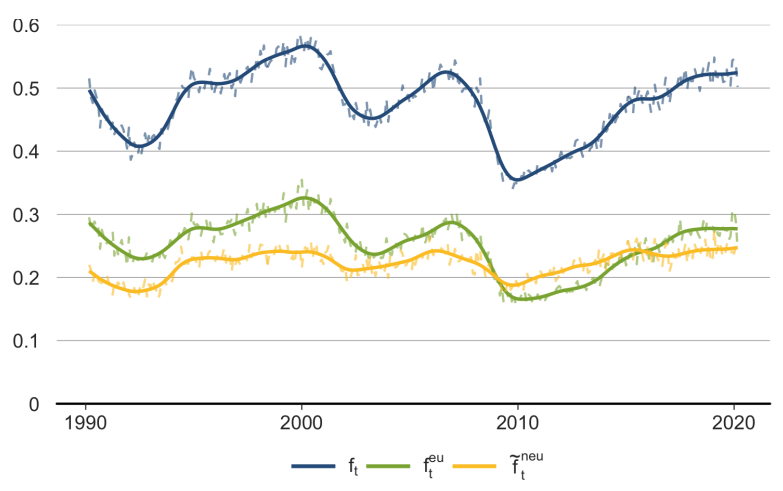

(b) Job Finding Rate

Figure A3: Separation rate: time varying and constant rates

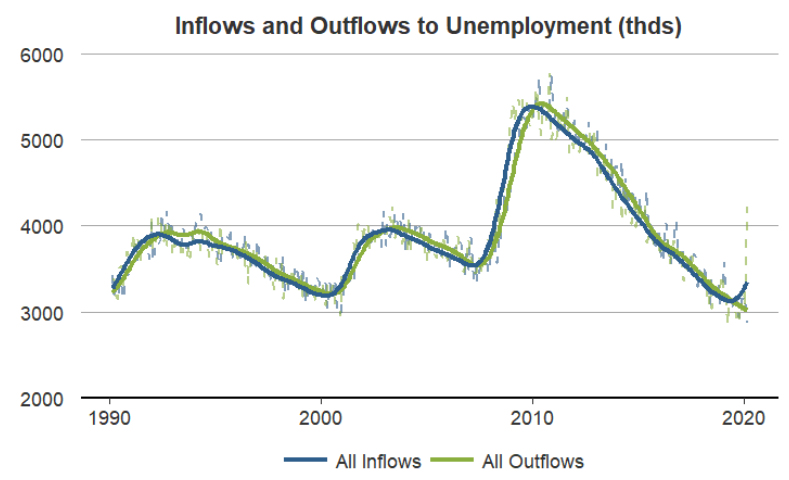

(a) Level

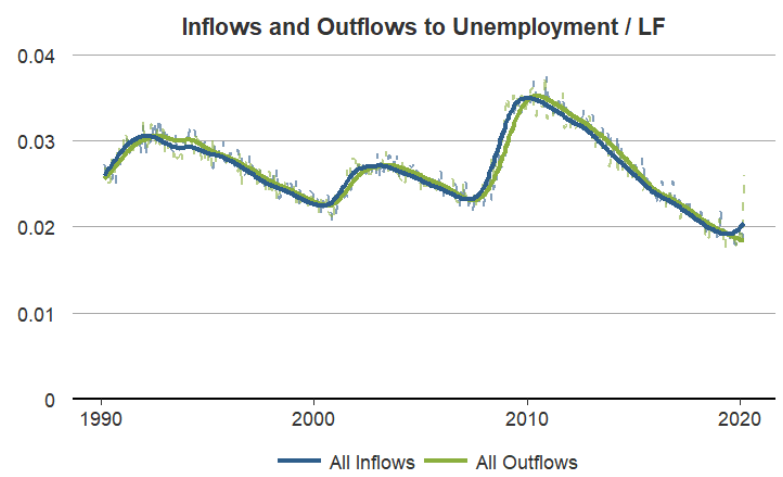

(b) Rate

Figure A4: $U^{\text {in }}$ and $U^{\text {out }}$ 


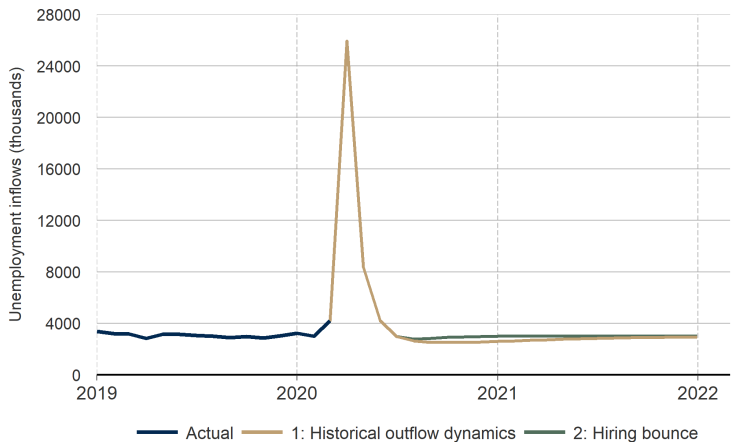

(a) Inflows

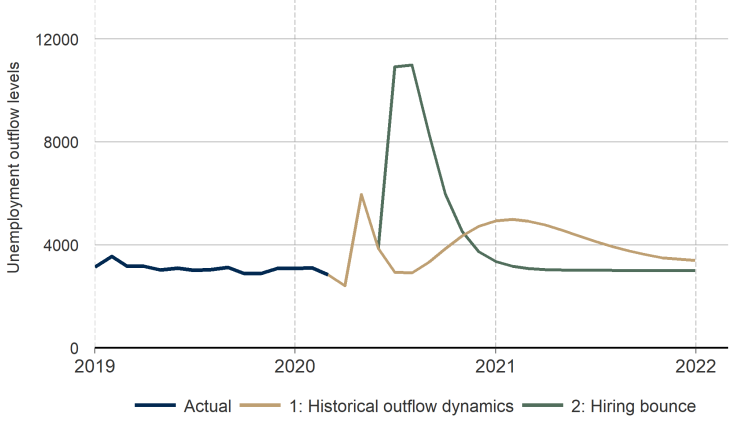

(b) Outflows $U_{t}^{\mathrm{Out}}$

Figure A5: Unemployment inflows and outflows during the outbreak, thousands

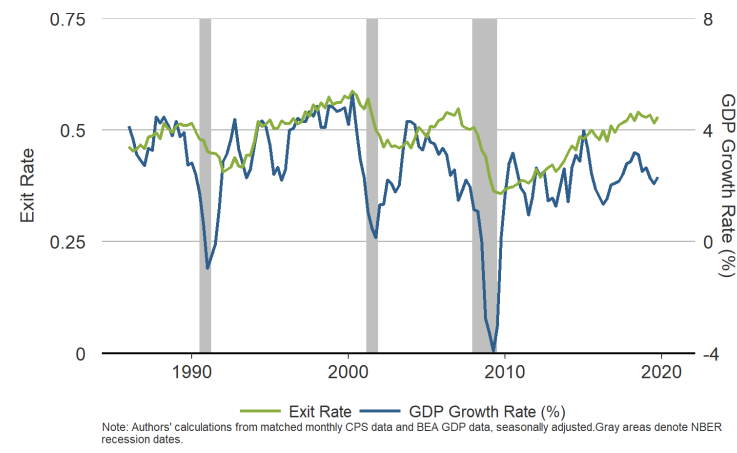

(a) $U$ exit rate (to $E$ or $N$ ) and GDP growth

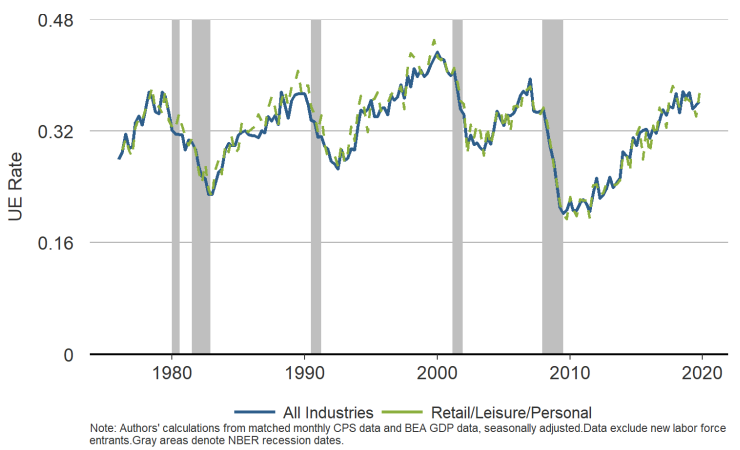

(b) Historical U to E rates, overall and service sector

Figure A6: Unemployment exit rates and GDP growth

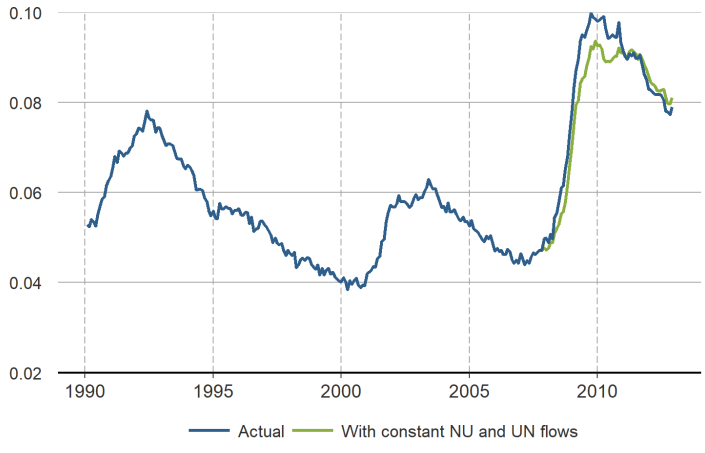

(a) Great Recession

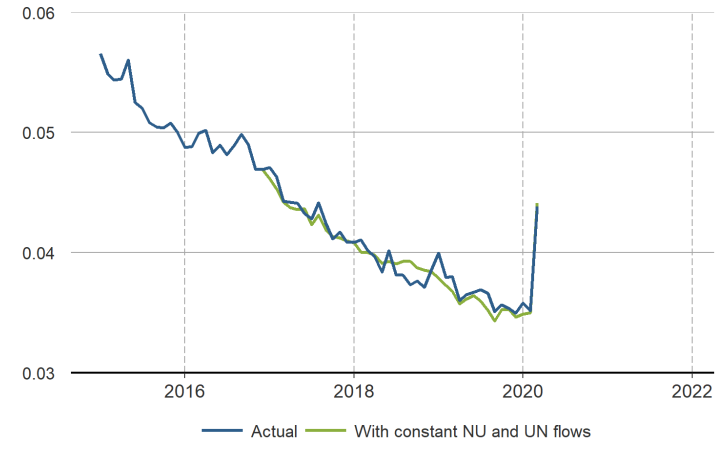

(b) Recent period

Figure A7: Unemployment rate: actual and imposing fixed $N U$ and $U N$ flows 


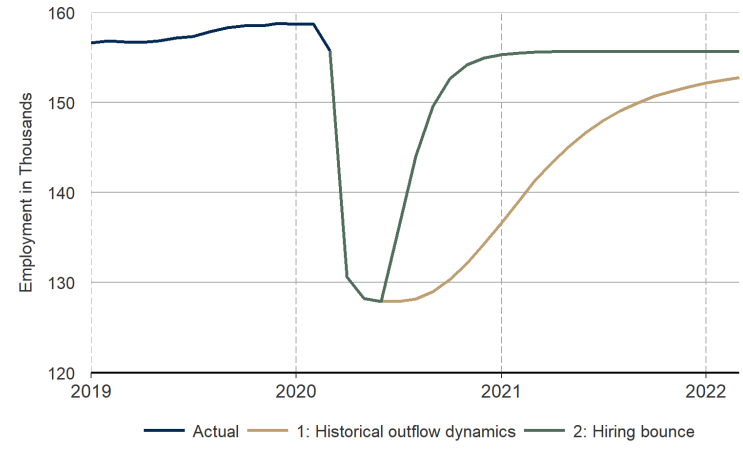

(a) Employment, thousands

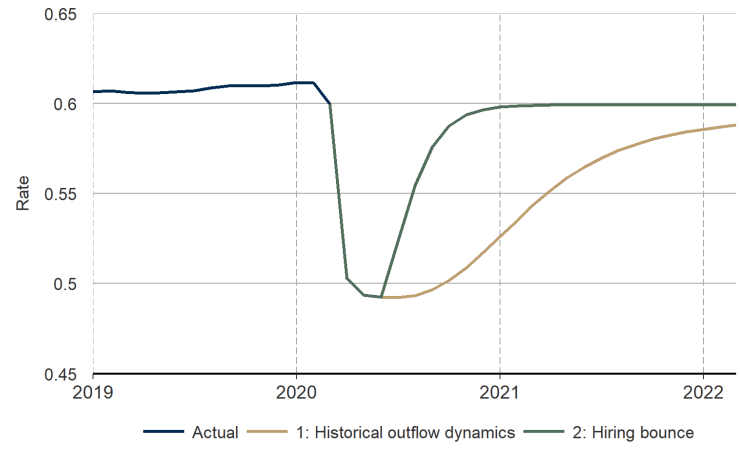

(b) Employment to working age population ratio

Figure A8: Employment, level and population ratio: "historical outflow dynamics" and "hiring bounce" scenarios

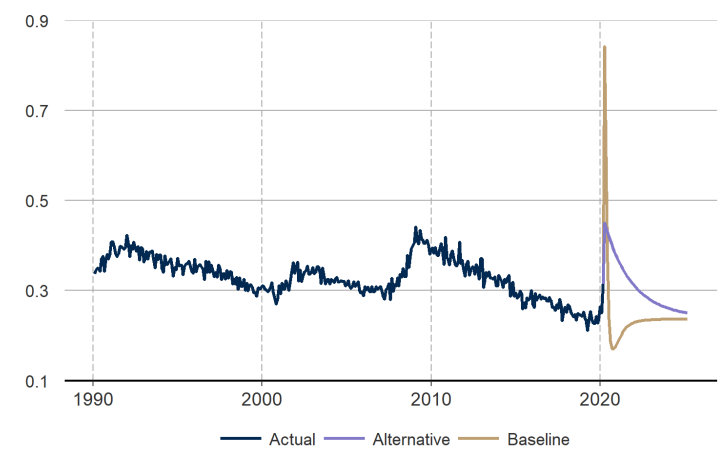

(a) EU share of employment outflows: $\tau_{E U, t}=\frac{E U_{t}}{E_{t}^{\text {Out }}}$

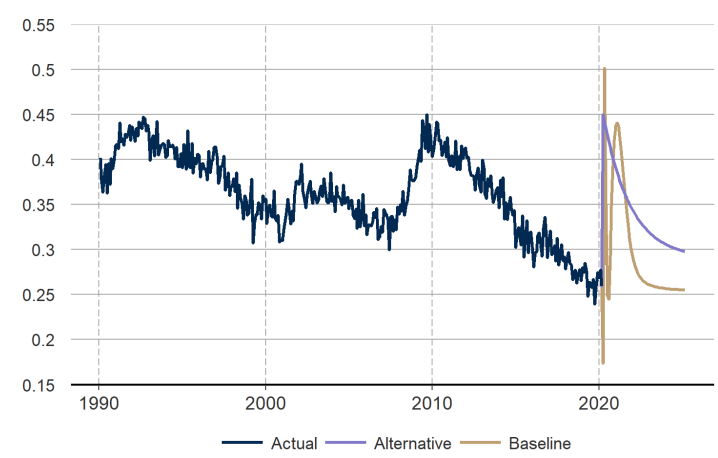

(b) UE share of employment inflows: $\tau_{U E, t}=\frac{U E_{t}}{E_{t}^{\text {Out }}}$

Figure A9: Unemployment margins of employment inflows and outflows: historical and COVID-19 scenarios 


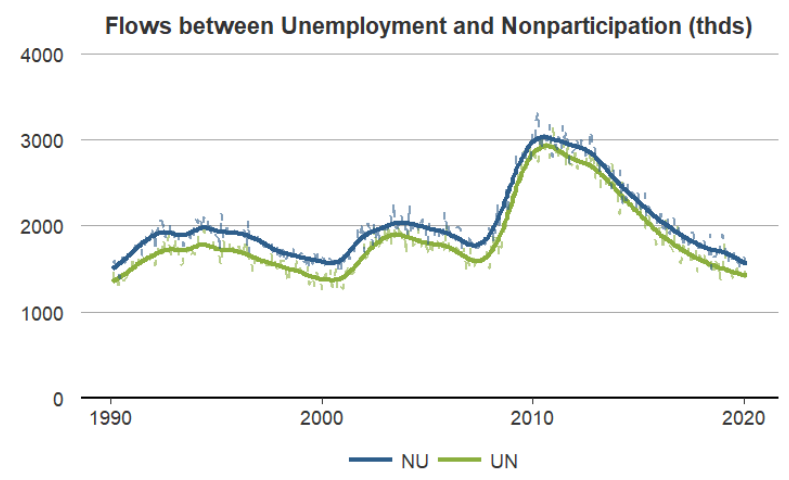

(a) Level

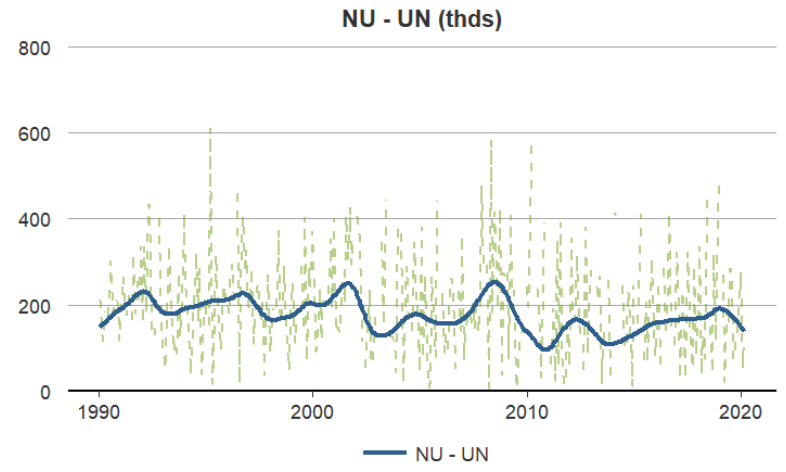

(b) Difference $N U-U N$

Figure A10: Unemployment margin of participation: $N U$ and $U N$ flows

\section{B Unemployment dynamic accounting equations}

- Unemployment and labor force, dynamic accounting equations:

$$
\begin{aligned}
U_{t} & =U_{t-1}+\left(N U_{t}+E U_{t}\right)-\left(U N_{t}+U E_{t}\right)+o_{t}^{u} \\
U_{t} & =U_{t-1}+U_{t}^{I n}-U_{t}^{O u t}+o_{t}^{u} \\
L F_{t} & =L F_{t-1}+\left(N U_{t}+N E_{t}\right)-\left(U N_{t}+E N_{t}\right)+o_{t}^{l} \\
L F_{t} & =L F_{t-1}+L F_{t}^{I n}-L F_{t}^{O u t}+o_{t}^{l}
\end{aligned}
$$

- $o^{l}$ and $o^{u}:$ other flows

- Unemployment rate dynamic accounting equation

$$
\begin{aligned}
\frac{U_{t}}{L F_{t}} & =\frac{U_{t-1}}{L F_{t-1}}\left(\frac{L F_{t-1}}{L F_{t}}\right)+\frac{U_{t}^{I n}}{L F_{t}}-\frac{U_{t}^{O u t}}{L F_{t}}+\frac{o_{t}^{u}}{L F_{t}} \\
u_{t} & =u_{t-1}+u_{t}^{I n}-u_{t}^{O u t}+\tilde{o}_{t}^{u} \\
-\tilde{o}_{t}^{u}=\frac{o_{t}^{u}}{L F_{t}}-u_{t-1}\left(\frac{L F_{t}-L F_{t-1}}{L F_{t}}\right) &
\end{aligned}
$$

- The inflow and outflows out of unemployment $U^{i n}$ and $U^{\text {out }}$, and $u^{\text {in }}$ and $u^{\text {out }}$ are plotted in Figure A4 (the unemployment rate residual $\tilde{o}_{t}^{u}$ is negligible, averaging 0.0001).

\section{B.1 Introducing separation and job finding rates}

\section{Separation rates}

- The unemployment inflow rate is expressed as a time varying rate $\delta_{t}$ of the population not unemployed:

$$
u_{t}^{I n}=\delta_{t}\left(1-u_{t-1}\right)
$$


- The inflow rate $\delta_{t}$ reflects component EU and NU rates $\delta^{e u}$ and $\delta^{n u}(P=N+E+U$ denotes the population, and $l f=L F / P$ the participation rate): $\mathrm{A} 3 \mathrm{~b}$

$$
\begin{aligned}
u_{t}^{i n} & =\frac{E U_{t}}{L F_{t}}+\frac{N U_{t}}{L F_{t}}=\left[\frac{E U_{t}}{E_{t-1}} \frac{E_{t-1}}{L F_{t-1}}+\frac{N U_{t}}{N_{t-1}} \frac{N_{t-1}}{L F_{t-1}}\right] \frac{L F_{t-1}}{L F_{t}} \\
u_{t}^{i n} & =\left[\delta_{t}^{e u}\left(\frac{L F_{t-1}-U_{t-1}}{L F_{t-1}}\right)+\delta_{t}^{n u}\left(\frac{P_{t-1}-L F_{t-1}}{L F_{t-1}}\right)\right] \frac{L F_{t-1}}{L F_{t}} \\
u_{t}^{\text {in }} & =\left[\delta_{t}^{\text {eu }}\left(1-u_{t-1}\right)+\delta_{t}^{n u}\left(\frac{1-l f_{t-1}}{l f_{t-1}}\right)\right] \frac{L F_{t-1}}{L F_{t}} \\
\delta_{t} & =\left[\delta_{t}^{\text {eu }}+\frac{\delta_{t}^{n u}}{1-u_{t-1}}\left(\frac{1-l f_{t-1}}{l f_{t-1}}\right)\right] \frac{L F_{t-1}}{L F_{t}} \\
\delta_{t} & =\delta_{t}^{\text {eu }}+\tilde{\delta}_{t}^{\text {neu }}
\end{aligned}
$$

- where $\tilde{\delta}_{t}^{\text {neu }}=\left[\frac{\delta_{t}^{n u}}{1-u_{t-1}}\left(\frac{1-l f_{t-1}}{l f_{t-1}}\right)+\delta_{t}^{e u}\left(1-\frac{L F_{t}}{L F_{t-1}}\right)\right] \frac{L F_{t-1}}{L F_{t}}$.

- For constant $P$ and LF: $\tilde{\delta}_{t}^{n e u}=\frac{\delta_{t}^{n}}{1-u_{t-1}}\left(\frac{1-l f}{l f}\right)$

- The time varying separation rates $\delta_{t}, \delta_{t}^{e u}, \delta_{t}^{n u}$ and $\tilde{\delta}_{t}^{n e u}$ are plotted in Figure A3a.

\section{Job finding rate}

- To introducing an outflow rate let

$$
u_{t}^{\text {Out }}=f_{t} u_{t-1}
$$

- The net outflow rate $f_{t}$ reflects underlying components $f_{t}^{u e} f_{t}^{u n}$ :

$$
\begin{aligned}
u_{t}^{\text {uut }} & =\frac{U E_{t}}{L F_{t}}+\frac{U N_{t}}{L F_{t}}=\left[\frac{U E_{t}}{U_{t-1}}+\frac{U N_{t}}{U_{t-1}}\right] \frac{U_{t-1}}{L F_{t-1}} \frac{L F_{t-1}}{L F_{t}} \\
u_{t}^{\text {out }} & =\left[f_{t}^{u e}+f_{t}^{u n}\right] u_{t-1} \frac{L F_{t-1}}{L F_{t}} \\
f_{t} u_{t-1} & =\left[f_{t}^{u e}+f_{t}^{u n}\right] u_{t-1} \frac{L F_{t-1}}{L F_{t}} \\
f_{t} & =\left[f_{t}^{u e}+f_{t}^{u n}\right] \frac{L F_{t-1}}{L F_{t}} \\
f_{t} & =f_{t}^{u e}+\left[f_{t}^{u n}+f_{t}^{u e}\left(1-\frac{L F_{t}}{L F_{t-1}}\right)\right] \frac{L F_{t-1}}{L F_{t}} \\
f_{t} & =f_{t}^{u e}+\widetilde{f}_{t}^{u n e} \\
\text { - where } \widetilde{f}_{t}^{\text {une }}=\left[f_{t}^{u n}+f_{t}^{u e}\right. & \left.\left(1-\frac{L F_{t}}{L F_{t-1}}\right)\right] \frac{L F_{t-1}}{L F_{t}}
\end{aligned}
$$

\section{Final dynamic equation for the unemployment rate}

$$
u_{t}=u_{t-1}+\delta_{t}\left(1-u_{t-1}\right)-f_{t} u_{t-1}+\tilde{o}_{t}^{u}
$$




\section{B.2 Times series estimates for separation and finding rate processes}

We proceed in three steps: (i)we remove fluctuations beyond a 10 year horizon with a bandpass filter (Christiano and Fitzgerald, 2003); (ii), we estimate an AR(3) for the finding rate $f_{t}$, and an $\mathrm{AR}(1)$ for the separation rate $\delta$; (iii) we simulate the impulse responses treating the sudden rise in April 2020 as the impulse. 